\title{
AVALIAÇÕES QUALITATIVAS E QUANTITATIVAS DE PLANTAS DANINHAS NA CULTURA DA SOJA SUBMETIDA AOS SISTEMAS DE PLANTIO DIRETO E CONVENCIONAL ${ }^{1}$
}

\author{
EDUARDO DE SÁ PEREIRA ${ }^{2}$, EDIVALDO D. VELINI ${ }^{3}$, LÍDIA RAQUEL DE CARVALHO ${ }^{4}$ e RITA C. S. MAIMONI-RODELLA ${ }^{5}$
}

\section{RESUMO}

Com o objetivo de avaliar os efeitos do método de preparo do solo e do controle de plantas daninhas em resteva de aveia preta (Avena strigosa), na cultura da soja (Glycine max cv. 'IAC 14 '), foi conduzido um experimento de campo na Fazenda Experimental Lageado - UNESPBotucatu - SP, em 1993/94. Os tratamentos de manejo do solo foram Plantio Direto e Plantio Convencional (preparado com uma aração e três gradagens). As formas de controle de plantas daninhas estudadas corresponderam a uma testemunha sem controle do mato; controle com uso exclusivo de herbicidas aplicados em préemergência $(0,28 \mathrm{~kg} / \mathrm{ha}$ de metribuzim + $1,29 \mathrm{~kg} / \mathrm{ha}$ de orizalin); controle com uso exclusivo de herbicidas aplicados em pósemergência $(0,25 \mathrm{~kg} / \mathrm{ha}$ de fluazifop- $p$-butil + $0,25 \mathrm{~kg} / \mathrm{ha}$ de fomesafen); controle com o uso conjunto dos tratamentos em pré e pós-emergência mencionados. Tanto no plantio direto quanto no convencional, utilizou-se glyphosate para a eliminação da aveia preta e das plantas daninhas antes da implantação da cultura. $\mathrm{O}$ delineamento experimental adotado foi de blocos ao acaso em parcelas subdivididas, com quatro repetições. Os tipos de manejo do solo foram aplicados às parcelas e os métodos de controle das plantas daninhas às sub-parcelas. Deve ser ressaltado que durante a fase inicial do ensaio, as chuvas foram escassas, limitando tanto o crescimento da cultura quanto a atuação dos herbicidas de pré-emergência e pósemergência. As avaliações baseadas na contagem do número de plantas $/ \mathrm{m}^{2}$, realizadas aos $14,28 \mathrm{e}$ 35 dias após a emergência da cultura da soja , indicaram diferenças entre os métodos de preparo do solo e os métodos de controle. Entre as espécies daninhas mais freqüentes, Brachiaria plantaginea e Amaranthus viridis foram as predominantes no sistema de plantio convencional; estas espécies apresentaram pequena importância no plantio direto, no qual predominou Euphorbia heterophylla. No plantio convencional, os herbicidas de pré-emergência proporcionaram melhor controle de A. viridis do que de $B$. plantaginea; o controle com herbicidas pós-emergentes foi insatisfatório para ambas espécies. No plantio direto, o controle de E. heterophylla foi insatisfatório em todos os sistemas de controle testados. O plantio direto apresentou sempre menor número total de plantas daninhas, sobretudo de gramineas. A germinação de plantas daninhas limitou-se ao período de até 15 dias após a emergência da cultura, nos dois sistemas de cultivo.

Palavras chave: Avena strigosa, cobertura morta, herbicidas, preparo do solo.

\footnotetext{
${ }^{1}$ Recebido para publicação em 12/6/99 e na forma revisada em 23/9/99. Parte da Dissertação de Mestrado apresentada pelo primeiro autor à FCA/UNESP, Botucatu/SP.

${ }^{2}$ Eng $^{\circ}$ Agr ${ }^{\circ}$ Ms. Sc., AER-INTA Coronel Suárez - Las Heras 1369 - (7540) Cnel. Suárez - (Pcia. de Buenos Aires) Argentina.

${ }^{3}$ Prof $^{\circ}$ Dr., Dept ${ }^{\circ}$ de Agricultura, FCA/UNESP. C.P. 237, CEP: 18603-970, Botucatu/SP..

${ }^{4}$ Prof $^{\text {a }}$ Dr $^{\text {a, }}$ Dept ${ }^{\circ}$ de Bioestatística, IB/UNESP, Rubião Júnior, CEP: 18.618-000, Botucatu/SP.

${ }^{5} \operatorname{Prof}^{\mathrm{a}} \mathrm{Dr}^{\mathrm{a},}$ Dept $^{\mathrm{o}}$ de Botânica, IB/UNESP, Rubião Júnior, CEP: 18618-000, Botucatu/SP.
} 


\section{ABSTRACT \\ Quantitative and qualitative weed evaluation of soybean crop in no-tillage and conventional tillage systems}

With the objective to evaluate the effects of different tillage systems and different methods of control on mulch of black oat (Avena strigosa) on evolution and control of weeds in soybean crop (cultivar 'IAC 14'), a field experiment was carried out in Fazenda Experimental Lageado - UNESP Botucatu - SP, in 1993/94. The different cultivation systems were no tillage and conventional tillage, and the last cultivation system was made with disk harrow and three tandem disk harrow. The weed control methods were: control (weedy check), pre-emergence herbicides $(0,28 \mathrm{~kg} / \mathrm{ha}$ of metribuzim $+1,29 \mathrm{~kg} / \mathrm{ha}$ of oryzalin), post-emergence herbicides $(0,25 \mathrm{~kg} / \mathrm{ha}$ of Fluacifop- $p$-butil $+0,25 \mathrm{~kg} / \mathrm{ha}$ of fomesafen) and pre and post-emergence treatments (with the four herbicides in the same rates). Glyphosate was applied for weed and black oat elimination before the crop establishment. The experimental design used was a randomized block arranged in split-plots scheme with four replications. The different cultivation systems were applied on plots and the different weed control on sub-plots. In the early stages of

\section{INTRODUÇÃO}

O desenvolvimento de programas racionais de controle de plantas daninhas tem se intensificado recentemente, visando gerar tecnologia que possa atender a critérios de sustentabilidade. Neste contexto, o manejo de plantas daninhas ocupa lugar de destaque.

Variações no sistema de cultivo ou de semeadura apresentam, como conseqüência, alterações nas populações de plantas daninhas que infestam as áreas agrícolas (Leguizamon, 1992). No plantio direto o solo não é mobilizado; os outros sistemas incluem o revolver do solo, cujas condições físicas, químicas e biológicas se alteram, podendo afetar a dormência e a crop development, the rain was scarce, limiting crop growth and performance of the preemergence herbicides. The number the weeds $/ \mathrm{m}^{2}$ was evaluated at 14, 28 and 35 days after soybean emergency, showing differences between cultivation systems and among different control systems. Brachiaria plantaginea and Amaranthus viridis were predominant on conventional tillage, and less important on no-tillage system; the most important species in this system was Euphorbia heterophylla. On the conventional system, preemergence herbicides were the best control for $A$. viridis than to $B$. plantaginea; the control with post-emergence herbicides was unsatisfactory in both tillage systems. On the no-tillage systems the control of $E$. heterophylla was unsatisfactory in all studied situations. No-tillage systems showed a smaller number of weeds than conventional systems. The germination of weeds was restricted until 15 days after crop emergency in both tillage systems.

Key words: Avena strigosa, mulching, herbicide, tillage.

distribuição das sementes, o que influencia a densidade e a composição florística da infestação que se desenvolve no terreno.

Uma série de estudos têm evidenciado a ocorrência de alterações qualitativas e quantitativas nas comunidades de plantas daninhas que se instalam em áreas submetidas a diferentes sistemas de cultivo. Podem-se citar os trabalhos de Almeida et al. (1983a, b), Almeida \& Rodrigues (1991), Cogle et al. (1991), Guerra \& Martinez (1991), Frink \& Thomas (1992) e Kinsella (1992), cujos resultados corroboram estas evidências.

$\mathrm{O}$ uso de coberturas mortas pode também interferir sobre a composição florística da comunidade infestante, pois apresenta influência 
sobre os fatores de quebra de dormência de sementes, favorecendo a germinação de algumas espécies e prejudicando a de outras. Tais efeitos podem ser de natureza física, alterando a temperatura ou a luz, por exemplo, ou química, por meio de relações alelopáticas (Velini \& Negrisoli, 2000).

Com base nestas evidências, este estudo teve como objetivo comparar a incidência de plantas daninhas na cultura da soja, submetida a diferentes modalidades de aplicação de herbicidas, quando foram utilizados dois sistemas de produção (plantio direto e convencional).

\section{MATERIAL E MÉTODOS}

O presente experimento foi instalado e conduzido na Fazenda Experimental Lageado, da Faculdade de Ciências Agronômicas - UNESP, Campus de Botucatu, estado de São Paulo, numa altitude de aproximadamente $855 \mathrm{~m}$, latitude $22^{\circ}$ $20^{\prime} \mathrm{S}$ e longitude $43^{\circ} 10^{\prime} \mathrm{W}$. A área total do experimento foi de $6.000 \mathrm{~m}^{2}$. O clima da região é classificado como Cwb de Koeppen, e o solo onde o experimento foi instalado é do tipo Terra Roxa Estruturada distrófica, textura argilosa, com relevo ondulado e declividade de 10\% (Carvalho et al., 1983).

A área experimental foi semeada em 20/04/1993 com aveia preta (Avena strigosa). No estado de grão pastoso a maduro (27/08/93), a aveia foi dessecada quimicamente com glyphosate, sendo cortada mecanicamente em 15/10/93 e posicionada sobre o solo. Foram utilizados, em média, $1.132 \mathrm{~kg} / \mathrm{ha}$ de matéria seca de aveia na área experimental. Nas parcelas submetidas ao plantio direto, a aveia foi mantida na superfície, enquanto nas parcelas onde se procedeu ao plantio convencional ela foi incorporada ao solo por meio de uma aração e três gradagens.

Foram utilizados 8 tratamentos resultantes da combinação entre sistemas de preparo de solo (plantio direto e convencional) e quatro condições em termos de controle das plantas daninhas: testemunha sem capina; herbicidas de préemergência $(0,28 \mathrm{~kg} / \mathrm{ha}$ de metribuzim + $1,29 \mathrm{~kg} / \mathrm{ha}$ de orizalin) aplicados no dia 4/11/93; herbicidas de pós- emergência $(0,25 \mathrm{~kg} / \mathrm{ha}$ de fluazifop-p-butil $+0,25 \mathrm{~kg} / \mathrm{ha}$ de fomesafen) aplicados no dia 3/12/93 no plantio convencional e no dia 15/12/93 no plantio direto, e o uso conjunto dos herbicidas de pré e pós-emergência. A vazão utilizada para os herbicidas de préemergência e de pós-emergência foi de 200 e 214 1/ha, respectivamente, e os bicos foram de jato plano, tipo leque 80.02 .

$\mathrm{O}$ experimento foi instalado em parcelas subdivididas, dispondo-se os sistemas de preparo do solo nas parcelas e os tipos de controle de plantas daninhas utilizados nas sub-parcelas. $\mathrm{O}$ delineamento experimental utilizado foi em blocos casualizados, com quatro repetições. Cada parcela teve área média de $670 \mathrm{~m}^{2}$, considerando-se áreas médias de $265 \mathrm{~m}^{2}$ para as sub-parcelas.

Foram realizadas avaliações na comunidade de plantas daninhas, com dez amostragens de $0,25 \mathrm{~m}^{2}$ (quadro de $0,50 \mathrm{x}$ 0,50 m), na área útil das sub-parcelas, em três épocas diferentes, 14, 28 e 35 dias após a emergência da cultura, para a determinação da composição específica da comunidade infestante e densidade de indivíduos. Foi também realizada esta avaliação, aos 14 D.A.E. nas testemunhas, com três amostragens de $1 \mathrm{~m}$ x $1 \mathrm{~m}$, onde previamente, a cultura foi eliminada quimicamente.

Todos os dados obtidos no experimento foram submetidos a análise de variância com desdobramento dos graus de liberdade de tratamentos. Os desdobramentos da interação “ métodos de preparo $\mathrm{x}$ métodos de controle" foram efetuados procurando-se isolar tanto o efeito do método de preparo dentro de cada método de controle, quanto o efeito do método de controle para cada método de preparo. Foram desdobradas interações significativas ao nível de $20 \%$. As comparações entre médias foram feitas com o auxílio do Teste "t" ao nível de $10 \%$ de significância. 


\section{RESULTADOS E DISCUSSÃO}

As espécies encontradas nos dois sistemas de preparo do solo (plantio direto e convencional) foram: guaxuma (Sida rhombofolia), mamona (Ricinus communis), trapoeraba (Commelina benghalensis), amendoim-bravo (Euphorbia heterophylla), caruru (Amaranthus viridis), carrapicho-de-carneiro (Acanthospermum hispidum), capim-marmelada (Brachiaria plantaginea), aveia preta (Avena estrigosa), corda-de-viola (Ipomea sp.), nabiça (Raphanus raphanistrum), carrapicho-rastreiro (Acanthospermum australe), capim-colchão (Digitaria horizontalis), capim-carrapicho (Cenchrus echinatus), picão-preto (Bidens pilosa). Foram analisadas as espécies encontradas em maior densidade nos dois sistemas, ou seja, Euphorbia heterophylla no plantio direto, Brachiaria plantaginea e Amaranthus viridis, no plantio convencional. As demais espécies de plantas daninhas apresentaram densidades muito baixas, o que não permitiu conclusões precisas com respeito à sua predominância em ambos sistemas de preparo do solo, embora sejam espécies potencialmente importantes.

Na Tabela 1 são apresentadas as densidades populacionais médias de Euphorbia heterophylla nas três avaliações realizadas e os principais resultados da análise estatística dos dados. A interação métodos de preparo (MP) $\times$ métodos de controle (MC) foi significativa aos 35 dias apenas. A análise da Tabela 1 indica densidades populacionais médias máximas já na primeira avaliação realizada em todas as condições testadas, evidenciando que esta espécie apresenta sua germinação concentrada no inicio do ciclo da cultura. Deve ser ressaltado que a aplicação dos herbicidas pós-emergentes foi realizada aos 20 e 29 dias, após a emergência da cultura no plantio convencional e plantio direto, respectivamente, indicando a adequação deste tipo de herbicida ao controle desta espécie nos dois sistemas de produção.
As densidades populacionais médias foram bastante superiores no plantio direto. Considerando exclusivamente as testemunhas e as parcelas com uso de herbicidas de pré-emergência as densidades populacionais médias de Euphorbia heterophylla foram significativamente superiores no plantio direto na última avaliação. Ainda sendo consideradas só as testemunhas e os sistemas de preparo do solo pode-se determinar uma maior população de E. heterophylla no plantio direto. Isto poder-se-ía atribuir a uma estimulação física, química e/ou biológica, das sementes desta espécie, em sistemas de não revolvimento do solo, onde ocorrem mudanças quanti e qualitativas das espécies predominantes.

Embora ainda não existam justificativas para este comportamento, resultados similares foram também observados por Almeida (1983b, 1985), Leguizamon (1992), Lorenzi (1984), Puricelli \& Tuesca (1994).

Os números de indivíduos nas testemunhas foram inferiores aos dos tratamentos com uso de herbicidas de pré-emergência. A possível justificativa é a eliminação de competidores, principalmente gramineas, pela ação desses herbicidas.

De forma similar à espécie anterior, os dados referentes às densidades populacionais médias de Amaranthus viridis e os principais resultados da análise estatística são apresentados nas Tabela 2. Os métodos de controle dentro do plantio convencional mostraram diferenças significativas, nas três épocas de avaliação sendo as parcelas com pré e pre + pós as de melhor resultado quanto à diminuição da população dessa espécie. Em todas as avaliações o número de plantas de $A$. viridis foi muito superior no plantio convencional, havendo concordância deste comportamento com o verificado por; Puricelli \& Tuesca (1994); Almeida (1983a, 1983b).

Também neste caso as densidades populacionais médias, sobretudo no plantio convencional, alcançaram estabilidade já na primeira avaliação indicando a germinação concentrada no início do ciclo da cultura. 
TABELA 1. Número de plantas de Euphorbia heterophylla/m². Médias e principais resultados da análise estatística dos dados.

\begin{tabular}{|c|c|c|c|c|c|}
\hline Tratamento & Controle & Prenaro & 14 dias & 28 dias & 35 dias \\
\hline 1 & Testemunha & $\mathrm{PC}$ & $1.60 \mathrm{a}$ & $0.80 \mathrm{a}$ & $1.10 \mathrm{a}$ \\
\hline 2 & Pré & PC & $3,06 \mathrm{a}$ & $0,30 \mathrm{a}$ & $0,30 \mathrm{a}$ \\
\hline 3 & Pós & $\mathrm{PC}$ & & & $0,90 \mathrm{a}$ \\
\hline 4 & Pré + pós & $\mathrm{PC}$ & & & $1,40 \mathrm{a}$ \\
\hline 5 & Testemunha & $\mathrm{PD}$ & $8,13 \mathrm{~A}$ & $10,30 \mathrm{~A}$ & $9,90 \mathrm{~B}$ \\
\hline 6 & Pré & PD & $18,13 \mathrm{~A}$ & $15,40 \mathrm{~A}$ & $20,40 \mathrm{~A}$ \\
\hline 7 & Pós & PD & & & $5,20 \mathrm{~B}$ \\
\hline 8 & Pré + pós & $\mathrm{PD}$ & & & $9,40 \mathrm{~B}$ \\
\hline \multicolumn{3}{|c|}{$\begin{array}{l}\text { Testemunha-PC } \\
\text { Testemunha-PD }\end{array}$} & $\begin{array}{l}1.60 \alpha \\
8.13 \alpha\end{array}$ & $\begin{array}{l}0.80 \beta \\
10.30 \alpha\end{array}$ & $\begin{array}{l}1.10 \beta \\
9.90 \alpha\end{array}$ \\
\hline \multirow{2}{*}{\multicolumn{3}{|c|}{$\begin{array}{c}\text { Plantio Convencional -PC } \\
\text { Plantio Direto - PD } \\
\end{array}$}} & $2.33 \mathrm{x}$ & $0,55 \mathrm{v}$ & $0.925 \mathrm{v}$ \\
\hline & & & $13,13 x$ & $12,85 \mathrm{x}$ & $11,23 x$ \\
\hline \multirow{2}{*}{\multicolumn{3}{|c|}{$\begin{array}{l}\text { Testemunha } \\
\text { Pré }\end{array}$}} & $4.86 \mathrm{e}$ & $5.55 \mathrm{f}$ & $5.50 \mathrm{f}$ \\
\hline & & & $10,60 \mathrm{e}$ & $7,85 \mathrm{e}$ & $10,35 \mathrm{e}$ \\
\hline \multicolumn{3}{|c|}{ Pós } & & & $3,05 \mathrm{f}$ \\
\hline \multicolumn{3}{|c|}{ Pré + pós } & & & $5,40 \mathrm{f}$ \\
\hline \multicolumn{3}{|c|}{ Valor de F } & 0,42 & 1.73 & 3,16 \\
\hline \multirow{2}{*}{\multicolumn{3}{|c|}{$\begin{array}{l}\mathrm{Pr}>\mathrm{F} \\
\mathrm{CV} \%\end{array}$}} & 0,5525 & 0,2361 & 0,0501 \\
\hline & & & 150,79 & 162 & 188,15 \\
\hline
\end{tabular}

Médias seguidas por letras iguais nas colunas, dentro de cada categoria, não diferem significativamente entre si (teste $\mathrm{t}$ ao nível de $10 \%$ )

TABELA 2. Número de plantas de Amaranthus viridis $/ \mathrm{m}^{2}$. Médias e principais resultados da análise estatística dos dados.

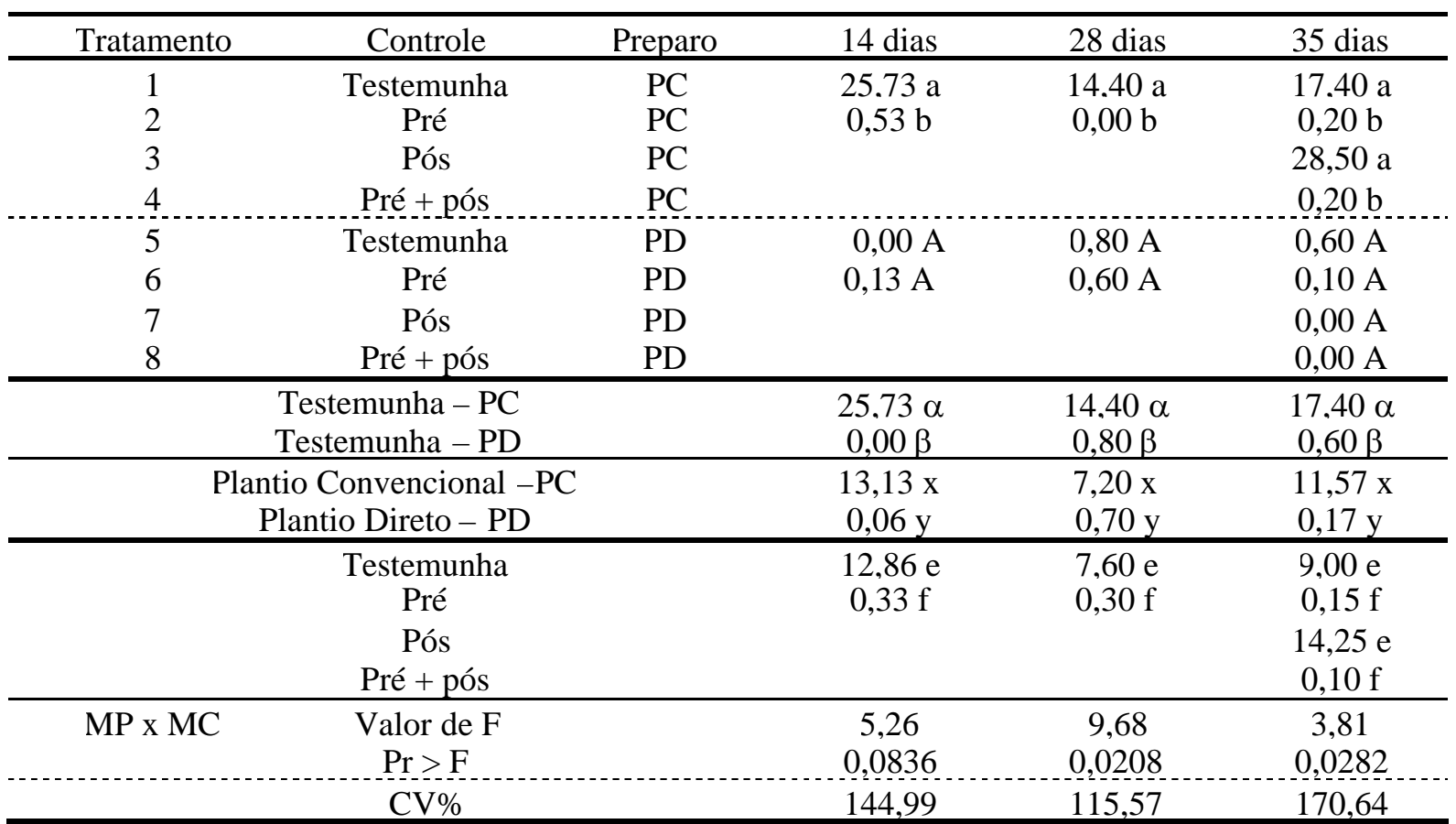

Médias seguidas por letras iguais nas colunas, dentro de cada categoria, não diferem significativamente entre si (teste t ao nível de $10 \%)$ 
Ficou evidente a elevada eficiência do tratamento pré-emergente no controle desta espécie em plantio convencional, contrastando com a baixa eficiência do tratamento pósemergente devido às más condições climáticas de aplicação e do tamanho das plantas. A justificativa para a baixa eficiência do fomesafen foi a elevada temperatura associada à baixa umidade relativa quando da aplicação e nos dias seguintes à mesma, além de se encontrarem, as espécies, em um estado de desenvolvimento avançado, com mais de quatro folhas. As densidades populacionais médias no plantio direto foram bastante baixas (inferiores a $1 \mathrm{planta} / \mathrm{m}^{2}$ ) não suportando conclusões precisas sobre os efeitos dos métodos de controle. Ainda se pode apreciar uma clara diminuição na população de $A$. viridis no sistema de plantio direto quando comparado com o convencional e nas testemunhas de ambos sistemas, indicando um efeito supressor do sistema de plantio direto nesta espécie. Efeitos estes que poderiam ser explicados pela diferenças nas condições físicas, químicas e/ou biológicas no sistema de plantio direto vs. convencional. Resultados similares foram obtidos por Almeida \& Rodrigues (1991).

Para a Brachiaria plantaginea a análise das médias dos tratamentos principais revelaram diferenças significativas entre os dois sistemas de preparo do solo, sendo a sua densidade populacional maior no sistema de plantio convencional, resultados estes obtidos também por Almeida (1985, 1988). Quando analisadas as médias dos tratamentos secundários, houve diferenças significativas aos 14 e 35 dias. Aos 14 dias o herbicida pré-emergente diferiu da testemunha e aos 35 dias os herbicidas pós e pré + pós diferiram da testemunha e do herbicida préemergente (Tabela 3), revelando uma melhor performance dos herbicidas pós e pré + pós no controle desta espécie.

As densidades populacionais médias de $B$. plantaginea, também no plantio convencional, alcançaram estabilidade já na primeira avaliação, revelando uma germinação concentrada no início do ciclo da cultura. Quando analisados aos 35 dias as médias do método de controle dentro do plantio convencional, a testemunha e o herbicida préemergente diferiram dos dois demais tratamentos, sendo os melhores pós e pré + pós. Quando comparadas as médias das duas testemunhas observou-se um claro efeito da palha de aveia na diminuição da população dessa espécie no plantio direto, podendo ser isto devido aos efeitos supressores causados pelas diferenças nas condições físicas, químicas e/ou biológicas que se apresentam entre os dois sistemas de preparo do solo (Almeida 1983b, 1985, 1988). B. plantaginea foi predominante no sistema de plantio convencional mostrando também uma germinação concentrada no início do ciclo da cultura.

Os resultados obtidos das análises de médias para os tratamentos principais, referentes ao total de plantas, revelaram diferenças significativas entre os dois sistemas aos $14,28 \mathrm{e}$ 35 dias, sendo maior o número de plantas no sistema convencional (Tabela 4). Resultados similares foram obtidos por Almeida (1983b, 1985, 1988), Lorenzi (1984), Kimsella (1992). Quando analisados os tratamentos secundários, houve diferenças significativas aos 14,28 e 35 dias, sendo que aos 14 e 28 dias o número total de plantas foi menor com o uso de herbicidas em préemergência. Aos 35 dias o número de plantas foi menor com os herbicidas usados, sendo o melhor tratamento com herbicidas aplicados em pré + pós-emergência.

Quando analisadas as médias dos métodos de controle aos 14, 28 e 35 dias para o sistema de plantio convencional o menor número total de plantas foi obtido com os herbicidas utilizados em pré + pós-emergência, revelando um melhor desempenho destes dois herbicidas juntos do que separados. Quando observadas as médias dos métodos de controle para o plantio direto não houve diferenças significativas para nenhuma interação. Para as médias das testemunhas do número de plantas nos dois métodos de controle detectou-se diferenças significativas, revelando um efeito da cobertura morta de aveia no controle das plantas infestantes para as três avaliações. 
TABELA 3. Número de plantas de Brachiaria plantaginea $/ \mathrm{m}^{2}$. Médias e principais resultados da análise estatística dos dados.

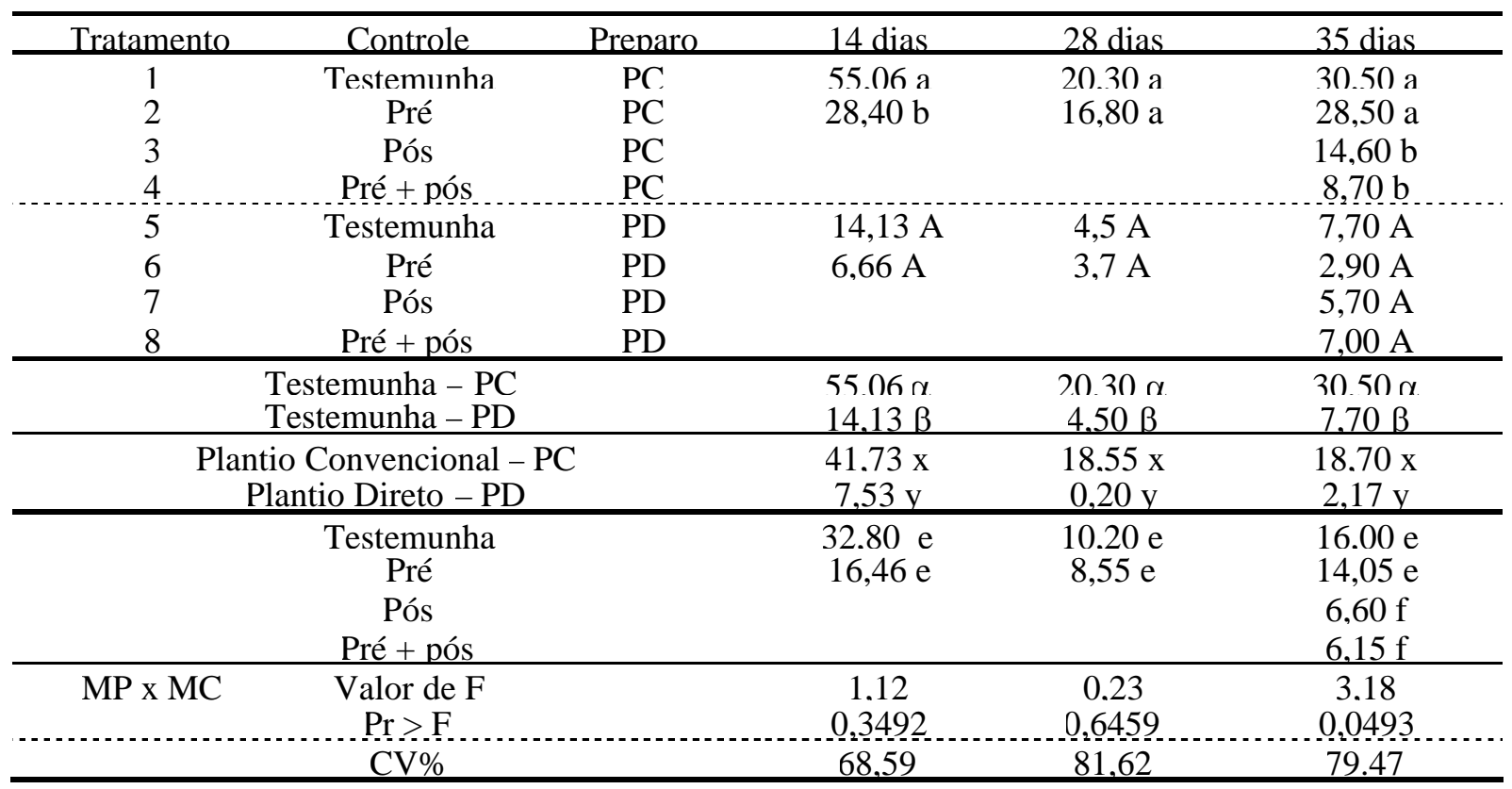

Médias seguidas por letras iguais nas colunas, dentro de cada categoria, não diferem significativamente (teste t ao nível de $10 \%)$

TABELA 4. Número de plantas totais $/ \mathrm{m}^{2}$ Médias e principais resultados da análise estatística dos dados.

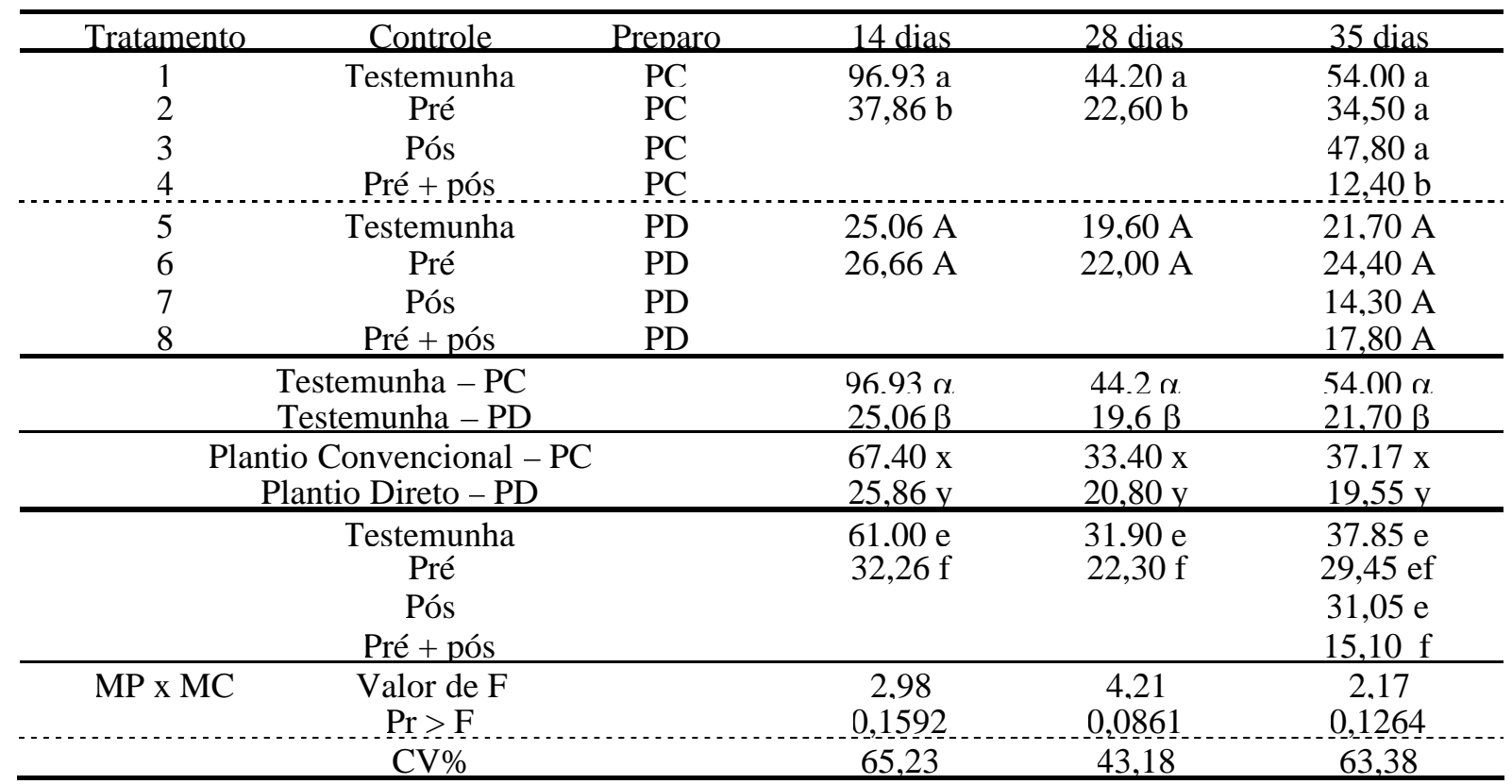

Médias seguidas por letras iguais nas colunas, não diferem estatisticamente entre si (teste t ao nível de $10 \%$ ). 
Resultados similares foram encontrados por Banks \& Robinson (1984), Almeida \& Rodrigues (1991), Gill et. al. (1992) e Marrochi et al. (1994), Kimsella (1992). Resultados contrários foram obtidos por Wrucke \& Arnold (1985) e por Frick \& Thomas (1992) com 5 e 2 anos de plantio direto respectivamente. Pleasant et al. (1992) observou maiores acúmulos de matéria seca em áreas de plantio direto.

Aos 14 dias, as avaliações realizadas nos pontos em que a cultura foi eliminada, indicaram densidades populacionais médias das várias espécies similares às verificadas para as testemunhas, nos dois sistemas de preparo do solo. Após esta avaliação as plantas daninhas e a cultura foram eliminadas com o uso de glyphosate (Tabela 5).
Inicialmente previa-se a realização de novas contagens e aplicações de glyphosate toda vez que emergissem quantidades substanciais de plantas nesses pontos, o que não ocorreu. Até a colheita da cultura, tais áreas permaneceram sem infestação.

Este resultado é de extrema importância, pois indica claramente que a germinação das plantas daninhas foi restrita até o $15^{\mathrm{o}}$ dia após a emergência da cultura, viabilizando o uso de herbicidas exclusivamente em pós-emergência. Esta germinação concentrada pode também justificar a existência de um período total de prevenção da interferência bastante curto para esta e outras culturas. Após este surto inicial de germinação, não há a necessidade de adoção de outras práticas de controle.

TABELA 5. Número médio de plantas $/ \mathrm{m}^{2}$ nas comunidades infestantes aos 14 D.A.E. nos locais onde foi eliminada a cultura, para os plantios convencional e direto.

\begin{tabular}{lcc}
\hline Espécies & Plantio Convencional & Plantio Direto \\
\hline Brachiaria plantaginea & 54,56 & 8,22 \\
Commelina benghalensis & 2,11 & 0,11 \\
Euphorbia heterophylla & 1,89 & 10,67 \\
Bidens pilosa & 0,33 & 0,00 \\
Raphanus raphanistrum & 1,11 & 0,22 \\
Amaranthus viridis & 12,89 & 0,22 \\
Acanthospermum hispidum & 0,67 & 0,22 \\
Ricinus communis & 0,44 & 0,00 \\
Ipomoea sp. & 0,33 & 0,22 \\
Sida rhombifolia & 0,22 & 0,56 \\
Digitaria horizontalis & 0,00 & 0,44 \\
Avena strigosa & 1,00 & 0,22 \\
Cenchrus echinatus & 0,33 & 0,33 \\
Glycine max & 0,00 & 0,78 \\
\hline
\end{tabular}

\section{LITERATURA CITADA}

ALMEIDA, F.S. Cobertura morta como forma de redução do uso de herbicidas. In: ENCONTRO NACIONAL DE PLANTIO DIRETO. 3, 1985, Ponta Grossa. Anais...,
Ponta Grossa: Cooperativa Central de Laticinios do Paraná, Fundação ABC, 1985. p. 118-29.

ALMEIDA, F.S. A alelopatia e as plantas. Londrina: Circ. IAPAR, n. 53, 1988. p.1-60. 
Avaliações qualitativas e quantitativas de plantas daninhas na cultura da soja submetida aos sistemas de plantio direto e convencional

ALMEIDA, F.S., RODRIGUES B.N. Comparação entre diferentes métodos de preparo do solo e infestação por plantas daninhas In: DERPSCH R. et. al. Controle da erosão no Paraná, Brasil: Sistemas de cobertura do solo, plantio direto e preparo conservasionista do solo. Eschborn: Deutsche Gesellschaftfur Technische Zusamm enarbeit. 1991; v. 11 cap5 p. 10811.

ALMEIDA, F.S., RODRIGUES, B.N., OLIVEIRA, V.F. Resultados de pesquisa da área de herbologia do IAPAR, da safra de 1982/83. Londrina: IAPAR, 1983b. 167p.

ALMEIDA, F.S., RODRIGUES, B.N., OLIVEIRA, V.F. Influence of winter crop mulches on weed infestation in mize. In: SYMPOSIUN ON WEED PROBLEMS IN THE MEDITERRANEAN AREA, 3, 1983a, Oeiras, Proceedings... Wageningem: EWRS, 1983, p. 351-58.

BANKS, P.A., ROBINSON E.L. The fate of oryzalin applied to straw-mulched and nonnulched soils. Weed Sci., v. 32, p 26972, 1984.

CARVALHO, W. A., ESPÍNDOLA, C. R., PACCOLA, A. A. Levantamento de solos da Fazenda Lageado, Estação Experimental "Presidente Médici". Botucatu: F.C.A. - UNESP, 1983. 95 p.

COGLE, A.L.; BATEMAN, R.J., HEINER, D.H., Conservation cropping systems for the semi-arid tropics of North Queensland, Australia. Aust. J. Exp. Agric., v. 31, p. $515-23,1991$.

FRICK, B.; THOMAS, A.G. Weed surveys in different tillage systems in southwester Ontario fiel crops. Can. J. Plant Sci., v. 72, p. 1337-47, 1992.
GILL, K.S. et. al. Influence of residue mulch, tillage and cultural practices on weed mass and corn yield from three field experiments. Soil \& Tillage Res, v. 24, p. 211-23, 1992.

GUERRA DORADO, J.A. ; MARTÍNEZ LÓPEZ, F. Importance of chemical weed control in alternate year cereal crops in the semi-arid conditions of spain. In: MEETING OF THE SPANISH WEED SCIENCE SOCIETY, Madrid, Sociedad Española de Malherbología p. 180-86, 1991.

KINSELLA, J. Siembra Directa: Efectos en largo plazo. In: CONGRESO INTERAMERICANO DE SIEMBRA DIRECTA $Y$ JORNADAS BINACIONALES DE CERO LABRANZA, 2, 1992, Villa Giardino, Conferencia... Rosario: Asociación Argentina de Productores en Siembra Directa, 1992 p. 12-5.

LEGUIZAMON E., Soja: El manejo de Malezas, el fenomeno Malezas. H. Cent. Desar. Rural, v.2, n. 16, p. 1, 1992.

LORENZI, H. Considerações sobre plantas daninhas no plantio direto. In: TORRADO, P.V. , ALOSI, R.R. Plantio direto no Brasil Campinas : Cargil, 1984. Cap. 2, p. $13-46$.

MAROCHI A.I., MIERLO C.V., GALLO P. Eficiência de flumetsulam aplicados sobre diferentes quantidades de palha, em sistema de plantio direto, no controle de dicotiledôneas na cultura da soja. IN: CONGRESSO BRASILEIRO DA CIÊNCIA DAS PLANTAS DANINHAS. XX, 1994, Florianópolis. Resumos... p. 768, 1994.

PLEASANT J.; Mc COLLUM R.E.; COBLE H.D. Weed management in a low input cropping 
system in the Peruviam Amazon region.

Tropical Agric., v 69, p. 250-9, 1992.

PURICELLI, E.C. \& TUESCA D. Malezas en sistemas de siembra directa. Departamento de Producción Vegetal, Facultad se Ciéncias Agrárias, Universidad Nacional de Rosário, 17 p., 1994.

VELINI, E. D., NEGRISOLI, E. Controle de plantas daninhas em canacrua. IN: CONGRESSO BRASILEIRO DA CIÊNCIA DAS PLANTAS DANINHAS, 22:2000. Foz do Iguaçu, PR. Palestra...Londrina, PR: SBCPD, 2000. p.148-164.

WRUCKE, M. A., ARNOLD, W. E. Weed species distribution as influenced by tillage and herbicides. Weed Sci., v. 40, p.429-33, 1992. 